\title{
POR UMA NOVA HISTORIOGRAFIA DO DIREITO INTERNACIONAL
}

\section{Juliana Müller*}

\section{Resumo:}

O Direito Internacional foi moldado de acordo com pretensões europeias de dominação colonial, e a historiografia da matéria representa ainda hoje estes interesses, naturalizando e legitimando uma pretensa superioridade de alguns povos sobre outros. O objetivo deste trabalho é propor meios pelos quais esta hegemonia pode ser contraposta, partindo da comprovação da Ocidentalização da matéria, explanando as consequências desta distorção e expondo alguns dos esforços na direção da descolonização da disciplina para, finalmente, averiguar como é possível tornar esta historiografia mais plural e justa.

Palavras-chave: Direito; Internacional; historiografia; decolonial; pós-colonial.

\section{TOWARDS A NEW HISTORIOGRAPHY OF INTERNATIONAL LAW}

\begin{abstract}
:
International law was shaped according to European pretensions of colonial domination, and the historiography of the field still represents these interests today, naturalizing and legitimizing an alleged superiority of some nations over others. The objective of this work is to propose means by which this hegemony can be countered, starting from the proof of the Westernization of the matter, explaining the consequences of this distortion and exposing some of the efforts towards the decolonization of the discipline to finally explore how it is possible to make this historiography more plural and fair.
\end{abstract}

Keywords: International; Law; historiography; decolonial; postcolonial.

\section{Introdução}

A historiografia do Direito Internacional clássico representa interesses de expansão colonial desde sua concepção, pretensões que seguem sendo respaldadas pela matéria ainda hoje. Ao desvendar como a disciplina validou e segue validando a exploração do Sul Global por parte das nações Ocidentais, é possível perceber que esta correlação perpetua uma narrativa hegemônica. O objetivo desta pesquisa, portanto, é propor formas pelas quais esta pode se tornar mais plural e diversificada.

\footnotetext{
Doutoranda no Programa de Pós-graduação em Direito da Universidade Federal de Santa Catarina. Pesquisadora do Centro de Pesquisas e Práticas Pós-coloniais e Decoloniais aplicadas às Relações Internacionais e ao Direito Internacional - Eirenè/UFSC. Mestre em Direito pelo PPGD/UFSC na área de Direito e Relações Internacionais. E-mail: j.muller@ posgrad.ufsc.br. Endereço Postal: PPGD/UFSC, Centro de Ciências Jurídicas, Campus Universitário, s/n - Trindade, Florianópolis - SC, CEP: 88040-900.
} 
Para cumprir com o objetivo proposto, primeiramente é exposto como o Direito Internacional se relaciona com os interesses Ocidentais desde seu princípio, e como este sistema se conserva na contemporaneidade a partir da preservação de mecanismos herdados da supremacia europeia. Em seguida, são apontadas algumas das consequências destas distorções, além de apresentadas algumas das correntes que se contrapõem à colonialidade da disciplina. Por fim, é analisado como é possível tornar esta narrativa mais heterárquica e justa.

A necessidade deste estudo está no fato de que a historiografia do direito está ligada à sua prática, e com o Direito Internacional não é diferente. Uma historiografia plural permite repensar a matéria, oferecer soluções alternativas, abrir novos caminhos de pesquisa e estimular soluções para problemas globais. Narrativas alternativas servem ao propósito de indagar ou mesmo romper com tradições consolidadas, encorajando o questionamento. Assim, novas versões sobre a história permitem a construção de diferentes conformações da organização jurídica internacional no presente e no futuro. Portanto, as contribuições para a historiografia do Direito Internacional devem ser entendidas como colaborações com a disciplina em si.

Com relação à metodologia empregada, trata-se de pesquisa de natureza básica, qualitativa, com fins explicativos e método de abordagem dedutivo a partir de meios bibliográficos e documentais. Ademais, salienta-se que para realização deste estudo foram utilizadas obras em idiomas estrangeiros, cuja tradução, em caráter não oficial, é de responsabilidade da autora deste trabalho.

\section{Uma raiz colonial}

A origem do Direito Internacional é centrada, segundo a maioria das correntes doutrinárias, no evento da Paz de Vestfália de 1648 (SHAW, 2003). No entanto, como apontam Silva e Perotto (2018), para os Estados colonizados não foi a paz europeia que estreou suas relações internacionais, mas a brutalidade da invasão de seus territórios. São amplas as evidências de que a disciplina foi moldada conforme as pretensões europeias de dominação colonial, interesses que seguem representados na historiografia da matéria ainda hoje.

O estudo da história do Direito Internacional nas salas de aula de todo o mundo baseia-se estritamente em autores europeus, ignorando outras formas de relações entre povos desenvolvidas em outras regiões do mundo. O professor de Teologia da Universidade de 
Salamanca, Francisco de Vitória (1483-1546), é considerado um dos primeiros juristas da história da matéria (SHAW, 2003), e suas obras são amplamente estudadas pelos discentes de direito. Como aponta Anghie $(2004 ; 2016)$, Francisco de Vitória justificou juridicamente a invasão espanhola na América e a subjugação dos povos indígenas, julgando-os como seres primitivos e ausentes de soberania, os quais deveriam ser civilizados e evangelizados.

Vitória colaborou de maneira essencial assim para a formulação da missão civilizadora, um entendimento segundo o qual o colonialismo justificou-se como um projeto para redimir povos atrasados e bárbaros, incorporando-os à civilização universal da Europa (ANGHIE, 2004; 2016). Outro autor de grande impacto historiográfico para o viés clássico da matéria é Hugo Grócio (1583-1645), jurista holandês reputado como o pai do Direito Internacional. Celebrado por sua contribuição para a paz na Europa, Grócio era funcionário da Companhia Holandesa das Índias Orientais e articulou doutrinas que legitimaram a ocupação europeia nas então chamadas Índias Ocidentais, defendendo a expansão do comércio e livre mercado. Sua obra A Lei da Guerra e da Paz é tida como leitura fundamental no estudo da história do Direito Internacional (ANGHIE, 2015; MUTUA, 2000; SHAW, 2003).

A relação destes dois célebres precursores do Direito Internacional com os interesses europeus de expansão territorial demonstra que o imperialismo é muito mais relevante para o desenvolvimento da matéria do que os acontecimentos políticos internos da Europa (referindo-se, aqui, especialmente à Paz de Vestfália), ainda que o pensamento clássico europeu exclua de sua historiografia o contexto colonial de sua própria concepção (SILVA e PEROTTO, 2018).

Após o período colonial, como ressaltam Silva e Perotto (2018), o Direito Internacional inseriu os povos explorados em um sistema que os marginaliza e desempodera, apresentando a contradição de que, para tornarem-se soberanos, precisariam subjugar-se às regras europeias. O processo de descolonização foi, por conseguinte, manipulado de forma a manter uma hierarquia de poder e exploração e estabelecer uma estrutura de dominação do Sul Global através do enraizamento de preceitos jurídicos Ocidentais (GROVOGUI, 1996).

A premissa de que o Direito Internacional foi convencionado por Estados em igualdade, quando apenas os países Ocidentais realmente participaram desta construção, demonstra claramente as naturalizações estruturais que governam o entendimento clássico do Direito Internacional. Neste sentido, Malcolm Shaw (2003), professor de direito na Universidade de Cambridge, refere em sua obra International Law que: 
E, ainda:

As bases do Direito Internacional (ou a lei das nações), como é entendido hoje, estão no desenvolvimento da cultura e da organização política ocidentais. O crescimento das noções europeias de soberania e do Estado-nação independente exigiu um método aceitável pelo qual as relações interestaduais pudessem ser conduzidas de acordo com padrões de comportamento comumente aceitos, e o Direito Internacional preencheu a lacuna (SHAW, 2003, p. 156, tradução e grifo da autora).

..a abordagem predominante das civilizações antigas era geográfica e culturalmente restrita. Não houve concepção de uma comunidade internacional de Estados coexistindo dentro de uma estrutura definida. O âmbito de qualquer "lei internacional" destas nações era extremamente limitado e o máximo que se poderia considerar seria a existência de certos ideais, como a santidade de tratados, os quais continuam hoje como elementos importantes da sociedade. Mas a noção de uma comunidade universal com seu ideal de ordem mundial não estava em evidência (SHAW, 2003, p. 158, tradução e grifo da autora).

O trecho exemplifica como o entendimento clássico da disciplina vê a raiz europeia do Direito Internacional como um aspecto natural e racional, como se o caminho para sua construção normativa fosse obviamente o da expansão dos valores Ocidentais. E, em relação à historiografia do Direito Internacional moderno, são igualmente muitas as formas pelas quais a naturalização e imposição de padrões Ocidentais podem ser identificadas.

A Organização das Nações Unidas, cuja criação é um importante marco para a disciplina contemporânea, foi concebida em 1945 sob o impacto dramático da Segunda Guerra Mundial, com o propósito de evitar outros futuros conflitos. Para este objetivo instituiu-se o Conselho de Segurança (CSNU), órgão encarregado de manter a paz e prevenir futuros atos de agressão. O CSNU compreendia, inicialmente, as quatro potências mundiais da época - Estados Unidos, Grã-Bretanha, União Soviética e China - os “Quatro Policiais”, os quais, como sugerira Franklin Roosevelt, então presidente dos Estados Unidos, operariam um sistema chamado "tutela dos poderosos", repartindo seus deveres de manutenção da segurança em cada região do globo (GARCIA, 2011).

A estas nações somou-se, posteriormente, a França, e o esboço de Roosevelt tornouse o que ainda hoje compreende os cinco membros permanentes do Conselho de Segurança (GARCIA, 2011). A Organização, portanto, pressupôs uma igualdade apenas formal, pois a composição dos postos permanentes do Conselho de Segurança ilustra fortemente a validação de hierarquias de poder pré-estabelecidas desde sua concepção e a articulação de meios de manutenção para as mesmas. Nesse sentido, Silva (2018) ressalta que:

...os países colonizadores foram fundadores da ONU e procuraram, desde o nascimento da Organização, preservar o sistema colonial utilizando-se, para isso, das plataformas multilaterais. Aliás, quando a ONU foi arquitetada, cerca de 750 milhões de seres humanos, ou seja, um terço da população mundial vivia sob o jugo 
do imperialismo, já que habitava em um território considerado não-autônomo ou administrado pelas potências coloniais (SILVA, 2018, p. 80).

Uma das claras controvérsias do CSNU consiste no fato de que o Apartheid na África do Sul foi instaurado em 1948 e o órgão agiu em conivência com as violações de direitos dos povos negros durante as três décadas ao não determinar sanções apropriadas ao regime de Pretoria. Apenas após o Levante de Soweto, em 1976, o CSNU se contrapôs efetivamente à segregação sul-africana (SILVA, 2018).

Ademais, a Organização proclama seus valores como universais, ideologia que, conforme Wallerstein (2006), justifica as políticas Ocidentais a partir do entendimento de que alguns povos - principalmente europeus e estadunidenses - são representantes de valores e verdades únicas, as quais devem ser levadas aos países pobres a fim de salvá-los das guerras e do terrorismo. Este universalismo, como refere Chimni (2006), corresponde a uma forma de dominação contemporânea, naturalizando uma visão de mundo eurocentrada. Mutua (2000) ressalta a contradição de que, se por um lado a Organização das Nações Unidas declara seus preceitos como universais, por outro, a conformação dos assentos permanentes de seu Conselho de Segurança da Organização Internacional contraria este princípio.

A Declaração Universal dos Direitos Humanos (DUDH), outro marco considerado fundamental para o Direito Internacional, é também uma prova da Ocidentalização da matéria. É incontestável que a DUDH simboliza um progresso na historiografia do DIP, tratando-se de um documento de elevado valor moral (SILVA, 2018). Seu discurso, entretanto, endossa a suposta superioridade de algumas nações quando prega que os países “civilizados" levem seu desenvolvimento para o Sul Global (WALLERSTEIN, 2006; CHIMNI, 2006). Ademais, como salienta Wallerstein (2006), os mesmos países que defendem os Direitos Humanos no mundo considerado subdesenvolvido são os que continuam a explorá-lo materialmente.

Neste sentido, Mutua (2001) afirma que o discurso de Direitos Humanos sustentado pelo Ocidente dentro de suas Universidades, da ONU e de Organizações Não-Governamentais (ONG's) traz ainda outros parâmetros que precisam ser identificados e criticados. Um deles é a ótica distorcida da vitimização, que mostra as pessoas oriundas do Sul Global como seres inertes diante das violações sofridas. Em contrapartida, o Ocidente figura como redentor, aquele que protege e salvaguarda os vulneráveis da tirania, cultura e tradições bárbaras de seu 
Estado. Desta forma, o discurso dominante de Direitos Humanos sustenta as estruturas de poder globais.

O Direito Internacional mainstream desempenha, assim, um papel significativo na legitimação do discurso Ocidental, associando-o à racionalidade, neutralidade e justiça. Este processo é protagonizado pelas instituições acadêmicas dos países dominantes, as quais, com seu prestígio e poder, desempenham uma influência fundamental na agenda global de pesquisa jurídica. Estudantes de Direito Internacional do mundo todo tendem a seguir o exemplo de livros e periódicos publicados nestas instituições, e esta leitura tem o poder de moldar os seus padrões de avaliação do contexto internacional, permitindo a reprodução inquestionada de eruditos que promovem interesses hegemônicos em suas obras (CHIMNI, 2006).

Neste sentido, Koskenniemi (2011) corrobora que a historiografia moderna do Direito Internacional narrada pelas elites europeias disseminou-se através das instituições universitárias ao redor do mundo. Esta versão Ocidental foi inculcada nos membros da academia, manifestando-se amplamente na forma como os eruditos percebem as relações internacionais. Galindo (2005) assevera que, após a Guerra Fria, não mais foram levantados questionamentos no que tange à aplicação de um Direito Internacional universal. Este se tornou pressuposto, restando às indagações discutir acerca de suas funções sem que a normativa em si necessitasse crítica sobre de sua natureza jurídica, explicações ou propósito.

Como visto, o Direito Internacional está entrelaçado durante todo seu desenvolvimento com pretensões de exploração e subjugação de algumas nações por parte de outras. Logo, é necessário que a disciplina volte a questionar estes preceitos e que sejam expostas as narrativas moldadas para atender aos interesses de dominação Ocidental, a fim de construir uma historiografia que inclua outros círculos jurídicos excluídos.

\section{As consequências de um DIP Ocidentalizado e os esforços para descolonizá-lo}

As narrativas omitidas pela historiografia clássica do Direito Internacional estão conectadas com a identidade coletiva e cultural das nações prejudicadas pela opressão Ocidental, comprovando a necessidade de abrir espaço para outras versões do passado. $\mathrm{O}$ silenciamento das violações cometidas contra os povos colonizados e escravizados prejudica a memória coletiva destas comunidades, evidenciando o porquê de a devida responsabilização dos países Ocidentais ter importância primordial no desenvolvimento de uma nova 
historiografia do Direito Internacional que estimule uma reconciliação global e permita relações mais justas entre os Estados.

A deturpação e supressão de memórias coletivas acarretam uma negação de pertencimento e identidade social. Redclift (2016), ao estudar a relação entre história, memória e identidade a partir da diáspora das comunidades Bihari (indianos da região de Bihar) nos Estados Unidos e no Reino Unido, revela que o significado da memória nas comunidades diaspóricas e transnacionais tem sido negligenciado, especialmente no que diz respeito à narração de eventos históricos.

O esquecimento gera grandes impactos em uma sociedade, e a história exerce um papel crucial na formação de um coletivo. Diásporas são, em certo aspecto, comunidades com imaginário transnacional, as quais compartilham uma variedade de significados. Esses entendimentos se manifestam não só nas condutas e discursos, mas também naquilo que não é dito, nas narrativas silenciadas de um povo. Desta forma, contar ou não contar uma história tem um profundo impacto na mobilização ou desmobilização de laços diaspóricos (REDCLIFT, 2016).

Pineteh (2017) também comprova este entendimento ao pesquisar os imigrantes somalis na África do Sul, os quais são majoritariamente solicitantes de asilo e refúgio. Conforme o autor, a história de guerras civis da Somália estruturou a socialização de seus emigrantes na nação sul-africana de forma tal que esta comunidade teve seu senso de identidade nacional seriamente afetado, tendo em vista os ataques xenófobos a que é exposta recorrentemente. As diásporas deixam um rastro de memória coletiva sobre outro lugar e tempo e a transformação destas lembranças em narrativas dá aos indivíduos uma sensação de pertencimento.

No caso dos povos negros que sofreram séculos de escravização, Cross (1998) corrobora que mesmo sobreviventes e seus descendentes podem sofrer os efeitos da transcendência intergeracional do trauma. A escravidão foi uma experiência multidimensional de longo prazo envolvendo múltiplas violações contra os povos africanos e afrodescendentes, e possui ainda correlação com as instâncias de opressão enfrentadas pelos negros no presente.

Estes efeitos, no entanto, não se devem apenas ao passado de escravidão, mas também pela continuidade das violências contra os povos negros na América. Neste sentido, Cross (1998) pondera que não apenas a condição de vida precária dos escravizados quando estes adquiriram a liberdade é responsável pela deterioração do bem-estar destes coletivos na 
contemporaneidade, mas também a herança colonial que deu seguimento às violações de direitos das comunidades negras.

Este impacto social e psicológico herdado pelas instituições coloniais é ratificado pelos silenciamentos historiográficos acerca da opressão e exploração conduzidas contra os africanos na América, omissão amplamente validada pelo Direito Internacional. Por outro lado, a ideia de que os europeus cumpriram uma "missão civilizatória" é amplamente difundida, exaltando-se os "descobrimentos" das regiões da América e outras conquistas. É por este motivo imperioso que esta narrativa seja questionada.

A partir desta conjuntura, Tourme-Jouannet (2013) critica o Direito Internacional clássico por compreender um corpo de lei estigmatizador e por refletir de forma distorcida o poder entre os Estados, fundamentando a discriminação entre nações civilizadas e não civilizadas. Para ilustrar estas distorções historiográficas, analisa-se o questionamento de Acharya (2014):

Por que vemos a Guerra Fria como uma "paz longa"? Porque as centenas de conflitos e milhões de vidas perdidas em campos de batalha durante a Guerra Fria ocorreram fora da Europa, no chamado Terceiro Mundo? Por que nós ignoramos as guerras coloniais? [...] Levar essas guerras em consideração desafiaria afirmações sobre a natureza pacífica das democracias liberais Ocidentais (ACHARYA, 2014, p. 648, tradução da autora).

Sob o prisma deste questionamento, Fassbender e Peters (2012) aduzem que a historiografia eurocêntrica do Direito Internacional está errada porque ela é incompleta. Ela ignora a violência que acompanhou a disseminação das regras do Ocidente e a destruição de outras culturas jurídicas resultante disso. É a história dos conquistadores e vitoriosos, e não das vítimas. Sua versão convencional ignora muitas experiências e relações legais entre comunidades autônomas não europeias, e estas omissões refletem na prática das relações jurídicas entre os Estados.

Muitos juristas vêm trabalhando contra a hegemonia, dedicando-se a desenvolver uma atitude crítica com relação ao ordenamento jurídico internacional, revelando os dispositivos legais que instrumentalizam a opressão ao Sul Global e como estes podem ser reformados. Estas correntes alternativas ao entendimento clássico da disciplina - outrora silenciadas ou invalidadas - originam-se no Sul Global e vêm ganhando espaço entre os debates acadêmicos e jurídicos, atingindo patamares de construção teórica amplamente reconhecidos pelas correntes doutrinárias ao redor do mundo. 
Um dos principais movimentos pela descolonização do Direito Internacional é o Third World Approaches to International Law, conhecido pela sigla TWAIL, o qual congrega esforços de diversos juristas pós-coloniais para elaborar uma interpretação do direito a partir de uma abordagem do Terceiro Mundo. O conceito de Terceiro Mundo twailiano deve ser entendido como um ataque à hegemonia Ocidental do mundo. O TWAIL, por sua vez, é a expressão deste mesmo confronto dentro da disciplina de Direito Internacional, tanto teórica como prática (MUTUA, 2000).

Como um dos juristas que compõe este movimento, Anghie (2006) afirma que os povos marginalizados pelo ordenamento jurídico internacional não devem dispensar totalmente o Direito Internacional. Segundo o autor, esta não é uma opção viável, tendo em vista que a disciplina vem demonstrando crescente capacidade de abranger as demandas do Terceiro Mundo por reconhecimento na comunidade internacional, permitindo que as violações conduzidas pelas nações Ocidentais nos países periféricos sejam questionadas e discutidas.

Também Chimni (2006) refere não ser a intenção dos juristas do TWAIL rejeitar completamente o Direito Internacional através de um ceticismo radical que veja todas as regras internacionais como vazias, violentas e sem propósito. Para o autor, é necessário reconhecer o escudo protetor que a normativa internacional oferece aos países menos poderosos, focando a teoria crítica nas contradições do sistema legal internacional. Torna-se imperiosa, portanto, uma visão intermediária: uma teoria de resistência que reconheça a necessidade de reformar o sistema dominante e que acredite na força dos movimentos sociais e políticos, dentre eles os que promovem a igualdade de raça, gênero e orientação sexual, bem como direitos ecológicos.

Logo, o discurso twailiano preocupa-se efetivamente em identificar as origens imperiais do Direito Internacional sem deixar de apreciar as ferramentas da matéria normativa que são úteis para a defesa dos interesses do Sul Global. O despertar destas identidades e aspirações traz um novo sistema de representações que influencia e condiciona o jeito como atores internacionais irão agir e reagir na esfera do Direito Internacional (TOURMEJOUANNET, 2013).

Neste contexto, Mutua (2000) afirma que o projeto do TWAIL defende a total representatividade das vozes de todos os povos - incluindo aqueles não representados por seus Estados, tendo em vista que estes constituem a maioria no Terceiro Mundo - através da plena 
democratização das estruturas de governança nacional e internacional. É imprescindível incluir o subalterno neste processo: aqueles que não se enquadram nos quadros do eurocentrismo e da modernidade devem integrar esta reconstrução democrática.

Denota-se, assim sendo, que o TWAIL colabora com os esforços por reconhecimento do Terceiro Mundo, pois pretende representar seu multiculturalismo e heterogeneidade no Direito Internacional através de uma abordagem anti-imperialista. A presença da pluralidade de vozes neste movimento dá também abertura para que a matéria normativa reconstrua sua historiografia de forma a respeitar a memória dos povos subalternos acerca do passado colonial.

Assim como o TWAIL, a necessidade de descolonizar o Direito Internacional é respaldada por diversos outros movimentos ao redor do globo. Estas iniciativas vêm ganhando cada vez mais espaço nas discussões jurídicas, afastando a predominância do discurso jurídico mainstream que reproduz a hegemonia e o imperialismo Ocidental. A ascensão destas novas representações e identidades no âmbito jurídico impulsionou o desenvolvimento de novas teorias acerca do Direito Internacional clássico - dentre elas as decoloniais e pós-coloniais. Além de criticar a tangente imperialista do aparato legislativo, muitas destas correntes defendem novas formas de interpretação normativa que possibilitem um empoderamento dos povos marginalizados.

\section{Por uma historiografia plural do Direito Internacional}

Como afirma Paoli (1992), a atividade de reconstruir a historiografia baseia-se na reconstituição de memórias que se perderam. O desafio de refazer a historiografia é, deste modo, possibilitar que experiências silenciadas e suprimidas de uma sociedade se reencontrem com a dimensão histórica. Assim, narrativas subalternas podem resgatar memórias coletivas de povos atingidos pelo colonialismo e escravidão e que seguem sofrendo com a opressão Ocidental orquestrada pela matéria. Estas versões plurais podem tem potencial para influenciar o Direito Internacional na direção de uma reconciliação global.

Nesta conjuntura, Galindo (2015) entende que o Direito Internacional contemporâneo funciona através da articulação entre o passado e o presente, na qual o segundo baseia-se no primeiro para validação ou para evolução. O autor menciona que em uma atitude estática, o passado precisa ser conhecido para que o presente e o futuro continuem a ser como ele; e em uma atitude dinâmica, o passado deve ser conhecido para que 
o presente e o futuro sejam diferentes dele. Estas posturas, no entanto, percebem o passado como uma verdade imutável.

Logo, é necessária uma terceira atitude por parte do jurista com relação ao passado: a percepção crítica. Esta ótica demonstra ser a mais adequada para operar mudanças profundas no Direito Internacional em favor daqueles tradicionalmente excluídos da ordem mundial. Galindo (2015) critica os historiadores do Direito Internacional por não se dedicarem a refletir sobre o próprio fazer histórico e sobre como a construção de narrativas tem afetado a prática do sistema normativo internacional; por não desenvolverem estudos mais aprofundados sobre a função da história, perguntando-se, por exemplo, para que ela existe ou serve; e por não questionarem determinadas noções, como a direcionalidade e a causalidade historiográfica.

Nesta mesma compreensão, Chimni (2007) declara que o caminho para o futuro percorre o passado. $\mathrm{O}$ autor afirma que a história do Direito Internacional tem sido objeto de exame pelos estudiosos pós-coloniais do Terceiro Mundo, tendo em vista a clara percepção de que, para transformar o presente e o futuro da disciplina, o passado deve ser entendido em toda a sua complexidade. Logo, à medida que o processo de descolonização avança, a história “paroquial” e Ocidental da matéria é cada vez mais repensada.

$\mathrm{O}$ reconhecimento do direito ao passado está, portanto, ligado intrinsecamente à consciência de que a história não é uma mesma para todas as sociedades, e deve assumir os riscos da diversidade, da ambiguidade das lembranças e esquecimentos, e mesmo de deformações variadas. Este reconhecimento tem o desafio de encontrar memórias sociais baseadas em valores simbólicos e orientar-se por uma produção de narrativas que não repudiem suas próprias historicidades (PAOLI, 1992).

A história do Direito Internacional é narrada a partir de preceitos europeus, desprezando os círculos jurídicos de outros continentes, e esta omissão acarreta uma grande ausência na história da disciplina. Os conhecimentos acerca destes outros sistemas legais são escassos e alheios à normativa internacional moderna. É necessário um maior diálogo entre a história e a teoria contemporânea com propósito de demonstrar como o direito colonial afeta aspectos do mundo atual. Um olhar crítico sobre o entendimento historiográfico da disciplina possibilita obter um instrumento de mudança social em favor daqueles que sofrem injustiças na ordem jurídica internacional (GALINDO, 2015).

As teorias pós-coloniais demonstraram que qualquer narrativa da modernidade que não leve em conta o impacto da experiência colonial na formação das relações propriamente 
modernas de poder é não apenas incompleta, mas também tendenciosa, pois foi precisamente a partir do colonialismo que se gerou esse tipo de poder (CASTRO-GÔMEZ, 2005). Tradicionalmente, a história do Direito Internacional tem sido profundamente eurocêntrica, gerando uma distorção que enfatiza a centralidade dos contextos Ocidentais - incluindo autores, ideias e eventos - e subestima a prática do Direito Internacional fora do Ocidente. Identificar esta deturpação requer a construção de uma leitura da origem e desenvolvimento do Direito Internacional que traga outras visões de mundo (LORCA, 2012).

Nesta perspectiva eurocêntrica, a formação de Estados-nação foi teorizada como expressão da homogeneização da população em termos de experiências históricas comuns. $\mathrm{O}$ que encontramos na história, no entanto, é que essa padronização consiste na formação de um espaço comum de dominação para o Sul Global (QUIJANO, 2005). Castro-Gômez (2005) aduz que a tarefa de uma teoria crítica neste contexto é exatamente tornar visíveis os mecanismos contemporâneos de produção de diferenças, ou seja, os conceitos das ciências sociais que se sustentam por um imaginário colonial de caráter ideológico. Conceitos binários - tais como barbárie e civilização, tradição e modernidade, mito e ciência, pobreza e desenvolvimento, entre tantos outros - permeiam completamente as narrativas.

Neste sentido, Silva e Perotto (2018) ratificam que a mentalidade imperialista que silencia acontecimentos históricos e conhecimentos situados fora do Ocidentalismo deve ser desfeita. Esta omissão, atualmente, surge na ausência da devida conexão entre a exploração econômica dos países em desenvolvimento e o passado. A academia segue tratando este tema com indiferença, como o fez com relação aos crimes do período colonial: o vocabulário jurídico não se altera senão para conservar um plano legislativo desigual.

Alegar uma objetividade total do historiador é negar a existência de agências escondidas - conscientes e subconscientes - nas diferentes versões sobre o passado. Galindo (2015) afirma que é certo que existem fatos incontroversos sobre o passado, e por isso o papel do historiador é subjetivo. Este trará os fatos para o presente e recriará uma outra realidade que não mais existe, sendo sua narrativa influenciada pelo cenário que o circunda. $\mathrm{O}$ que a historiografia do Direito Internacional necessita, portanto, é abrir portas para as visões de mundo plurais, permitir que pessoas que pensem de maneiras diferentes possam produzir compreensões historiográficas divergentes.

Por isto, o historiador crítico do Direito Internacional também possui importante função ética de apresentar o passado não a partir de uma suposta neutralidade, mas assumindo 
sua subjetividade. Trata-se de um compromisso com o pluralismo de valores e diversificação de narrativas, que evidencia que não há interpretações infalíveis ou indiscutíveis (GALINDO, 2015). Neste contexto, Anghie (2004) refere que - em contraste com as narrativas convencionais estabelecidas pelo Ocidente - é necessário contar versões alternativas: histórias de resistência ao poder colonial e o ponto de vista dos povos subjugados pelo imperialismo do sistema jurídico internacional.

Tourme-Jouannet e Peters (2014) entendem que essa consciência relativista deve ser inerente ao trabalho do historiador contemporânea do Direito Internacional, e concede uma importância crescente às práticas e fundamentos epistemológicos envolvidos na edificação de narrativas, bem como às identidades pessoais e profissionais de quem as constrói. A percepção de que a subjetividade do historiador afeta o modo como certa questão investigada é compreendida resulta na possibilidade de diversas abordagens acerca de um evento passado.

O entendimento sobre a possibilidade de múltiplas compreensões acerca de um mesmo fato traz a alternativa de construir teorias oriundas do Sul Global. Nesta conjuntura, Rajagopal (2005) defende a viabilidade de desenvolver a estrutura do Direito Internacional a partir de uma historiografia do Terceiro Mundo que conduza a uma teoria dos povos. Isto porque a narrativa do Direito Internacional tem sido escrita até a contemporaneidade a partir do ponto de vista dos Estados, excluindo muitas sociedades deste entendimento.

Neste sentido, Silva e Bodenmuller (2018) asseveram que é preciso abrir espaço para as vozes e visões silenciadas na relação entre os Estados e na interação entre os povos. A decolonialidade, conforme os autores, constitui um caminho central neste sentido, pois permite uma perspectiva analítica que abrange a ascensão de movimentos contra hegemônicos que se oponham às estruturas de poder hierarquizadas. Este espaço epistemológico fundamenta a legitimação de civilizações não Ocidentais e estruturas plurais nas relações internacionais.

Da mesma forma, Chimni (2006) entende que as histórias de resistência devem fazer parte das narrativas do Direito Internacional. É necessário abranger a crítica do Terceiro Mundo à abordagem neoliberal da lei internacional e desenvolver alternativas adequadas para integrá-las à erudição Ocidental. $\mathrm{O}$ autor refere que as colaborações dos povos subalternizados devem ser utilizadas para reconstruir a normativa, a fim de que esta aborde as preocupações dos grupos marginalizados e excluídos. É preciso, desta forma, que estes coletivos também elaborem sugestões concretas para mudanças no regime legal. 
Este posicionamento como agentes ativos é primordial para alcançar-se um direito pluriversal e heterárquico, o qual inclua as diversas singularidades e cosmovisões. Este conjunto jurídico seria mais adaptável e flexível, propiciando a configuração de uma paz construída por todos (SILVA; BODENMULLER, 2018). Além disso, Anghie (2006) critica os países do Terceiro Mundo por terem engajado em práticas coloniais dentro de suas próprias fronteiras, com relação, por exemplo, aos povos indígenas. Portanto, além de abranger o interesse dos países marginalizados, uma reconstrução do Direito Internacional deve também chegar aos povos que são excluídos dentro dessas nações.

Nesta conjuntura, Chimni (2007) pondera acerca de uma alienação do Direito Internacional com relação aos povos subalternos. Segundo o autor, a formalidade da disciplina a distancia de abordar apropriadamente as diversas sociedades do Terceiro Mundo sem certo grau de negligência e negação da vida cotidiana destes povos. Esta invisibilidade é decorrente dos preceitos capitalistas e modernos que permeiam o ordenamento internacional na contemporaneidade, os quais fecham os olhos para a miséria das comunidades, focando apenas no desenvolvimento econômico Estatal. Ainda que iniciativas - tal como a promoção dos Direitos Humanos - tentem responder a este cotidiano dos povos do Sul Global, suas ações são severamente limitadas pelas exigências de uma economia global imperialista. Isto ocorre pela falsa concepção de que através deste "desenvolvimento" neoliberal é que as sociedades poderão atingir patamares de bem-estar social e justiça (CHIMNI, 2007).

Para Chimni (2007), o futuro do Direito Internacional será determinado pela forma como o seu passado será interpretado. A historiografia da disciplina não deve ser negligenciada, e o autor pondera duas possibilidades: ou as narrativas de resistência ao Direito Internacional colonial e neocolonial se tornarão parte integrante da história da matéria, ou a historiografia imperialista será abordada de maneira a minimizar seu caráter destrutivo. Neste caso, os relatos acerca das conquistas dos impérios europeus seriam equilibradas com a acusação das violências perpetradas pelos colonizadores. Através destas alternativas, é concebível o surgimento de uma história global democrática do Direito Internacional escrita por acadêmicos que admitem a face opressora da matéria.

Neste entendimento, Silva e Perotto (2018) consideram que

Para mudar os ventos que conduzem o caminhar do Direito Internacional, faz-se necessário, igualmente, revisar e reconstruir a disciplina a partir da inclusão e do empoderamento daqueles que foram excluídos ou marginalizados durante os processos historiográficos dominantes. A revisão servirá para dar luz aos muitos exercícios de resistência ao Direito Internacional colonial e neocolonial e incorporá- 
los na trajetória do Direito Internacional, por meio da assimilação de práticas, memórias, sujeitos e conceitos não-Ocidentais (SILVA e PEROTTO, 2018, p. 148).

Portanto, como aduz Galindo (2005), o que se faz com o passado não está no passado: as narrativas acerca do passado possuem funções prospectivas na atualidade. Logo, o debate sobre o colonialismo e o eurocentrismo na historiografia do Direito Internacional é imprescindível não apenas para visibilizar o sofrimento de pessoas e povos oprimidos por esta hegemonia, mas também para atribuir à história da disciplina o importante papel de auxiliar na construção de agendas para o presente e para o futuro. Estabelece-se, assim, uma crítica à manutenção dessas estruturas e a opção por um sistema jurídico diferente.

\section{Conclusões}

A partir do estudo das diferentes formas pelas quais o Direito Internacional foi delineado conforme as pretensões de dominação Ocidental foi possível avaliar como a historiografia hegemônica da matéria influi para sustentar estas formas de opressão na contemporaneidade. Como restou evidenciado, cada vez mais juristas se debruçam sobre a narrativa eurocentrada da matéria a fim de identificar suas omissões e distorções, propondo novas formas de análise crítica para o desenvolvimento de uma versão plural do passado, a qual não se limite à "história do vencedor".

Dentre as formas pelas quais a historiografia do Direito Internacional pode ser descolonizada, destacou-se a necessidade de compreender a subjetividade do narrador e do rompimento com a ideia de uma história única de verdade universal, bem como do afastamento de conceitos e linguagens que colaborem como a exclusão e homogeneização da disciplina. Ademais, restou claro que esta nova versão deve ser construída por fontes até então subalternizadas, edificando um Direito Internacional pluriversal e heterárquico que represente o interesse não somente de todos os Estados, mas também de todas as coletividades dentro destes.

\section{Referências}

ACHARYA, Amitav. Global International Relations and Regional Worlds: a new agenda for international studies. Em: International Studies Quarterly. v. 58. n. 4. p. 647-59, 2014. Disponível em: https://www.researchgate.net/publication/269041431_Global_International_Relations_IR_and _Regional_Worlds_A_New_Agenda_for_International_Studies. Acesso em: 6 mar. 2020. 
ANGHIE, Antony. Hacia un Derecho Internacional Poscolonial. Em: Derecho y Crítica Social, v. 2, p. 71-99, 2015. Disponível em: https://derechoycriticasocial.files.wordpress.com/2016/08/3-anghie-2016.pdf. Acesso em: 5 mar. 2020.

ANGHIE, Antony. Imperialism, Sovereignty and the Making of International Law. New York: Cambridge University Press, 2004. Disponível em: https://kingdomofhawaii.files.wordpress.com/2011/04/anghie-imperialism-sovereignity-andthe-making-of-international-law.pdf. Acesso em: 13 mar. 2020.

ANGHIE, Antony. La evolución del derecho internacional: realidades coloniales y poscoloniales. Em: ANGHIE, Antony; KOSKENNIEMI, Martti; OXFORD, Anne (Ed.). Imperialismo y Derecho. Bogotá: Siglo del hombre editora, 2016. Disponível em: https://www.academia.edu/5894701/Imperialismo_y_Derecho_Internacional_Historia_y_Leg ado_English_Imperialism_and_International_Law_History_and_Legacy_Luis_Eslava_Lilian a_Obregón_René_Urueña_eds_Siglo_del_Hombre_Editores_2016_.Estudio_Preliminar_Im perialismo_s_y_Derecho_s_Internacional_es_Ayer_y_Hoy. Acesso em: 7 mar. 2020.

ANGHIE, Antony. The evolution of international law: Colonial and postcolonial realities. Em: Third World Quarterly, v. 27, n. 5, p. 739-753, 2006. Disponível em: https://collections.lib.utah.edu/dl_files/fb/5e/fb5ecb0217f1089ce9d43ca244de1c422bb752cb. pdf. Acesso em: 5 mar. 2020.

CASTRO-GÔMEZ, Santiago. Ciências sociais, violência epistêmica e o problema da invenção do outro. Em: A colonialidade do saber: eurocentrismo e ciências sociais. Perspectivas latino-americanas. Edgardo Lander (org). Coleção Sur Sur. Buenos Aires: CLACSO, 2005. Disponível em: http://biblioteca.clacso.edu.ar/clacso/sursur/20100624102434/9_CastroGomez.pdf. Acesso em: 6 mar. 2020.

CHIMNI, B. S. The past, present and future of international law: a critical third world approach. Em: Melbourne journal of international law, v. 8, n. 2, p. 499-515, 2007. Disponível em: https://law.unimelb.edu.au/_data/assets/pdf_file/0010/1683145/Chimni.pdf. Acesso em: 10 mar. 2020.

CHIMNI, B. S. Third World Approaches to International Law: A Manifesto. Em: International Community Law Review, 8: 3-27, 2006. Disponível em: https://www.jnu.ac.in/sites/default/files/Third\%20World\%20Manifesto\%20BSChimni.pdf.

Acesso em: 10 mar. 2020

CROSS, William E. Black Psychological Functioning and the Legacy of Slavery. Em: DANIELI, Yael (Ed.). International Handbook of Multigenerational Legacies of Trauma. Boston: Springer, 1998.

FASSBENDER, Bardo; PETERS, Anne. Introduction: Towards a Global History of International Law. Em: The Oxford Handbook of the History of International Law. Editado por Bardo Fassbender, Anne Peters, Simone Peter e Daniel Högger. Oxford: Oxford University Press, 2012.

GALINDO, George Rodrigo Bandeira. Para que serve a história do direito internacional? Em: Revista de Direito Internacional, Brasília, v. 12, n. 1, 2015 p. 338-354. Disponível em: https://www.publicacoesacademicas.uniceub.br/rdi/article/view/3368. Acesso em: 10 mar. 2020. 
GARCIA, Eugênio Vargas. De como o Brasil quase se tornou membro permanente do Conselho de Segurança da ONU em 1945. Em: Revista Brasileira de Política Internacional, 54 (1), p. 159-177, 2011. Disponível em: https://www.scielo.br/pdf/rbpi/v54n1/v54n1a10.pdf. Acesso em: 5 mar. 2020.

GROVOGUI, Siba N. Sovereigns, Quasi Sovereigns, and Africans Race and SelfDetermination in International Law. Em: Borderlines, vol. 3. Minneapolis: University of Minnesota Press, 1996. Disponível em: https://www.jstor.org/stable/10.5749/j.cttttb5p. Acesso em: 6 mar. 2020

KOSKENNIEMI, Martti. Histories of international law: dealing with eurocentrism. Em: Rechtsgeschichte, Frankfurt, v. 19, p. 152-176, 2011. Disponível em: https://www.researchgate.net/publication/254885929_Histories_of_International_Law_Dealin g_with_Eurocentrism. Acesso em: 10 mar. 2020.

LORCA, Arnulf Becker. Eurocentrism in the History of International Law. Em: The Oxford Handbook of the History of International Law. Editado por Bardo Fassbender, Anne Peters, Simone Peter e Daniel Högger. Oxford: Oxford University Press, 2012.

MUTUA, Makau. Savages, Victims and Saviors: The Metaphor of Humam Rights. Em: Harvard Internacional Law Journal, v. 42, n. 1, p. 201-245, 2001. Disponível em: https://www.semanticscholar.org/paper/Savages\%2C-Victims\%2C-and-Saviors\%3A-The-

Metaphor-of-Mutua/a537cf06ec32a344ddca1bd9d5082eb223855f52. Acesso em: 7 mar. 2020.

MUTUA, Makau. What is Twail? American Society of International Law, Proceedings of the 94th Annual Meeting, p. 31-39, 2000. Disponível em: https://digitalcommons.law.buffalo.edu/cgi/viewcontent.cgi?article $=1559 \&$ context=journal_a rticles. Acesso em: 7 mar. 2020.

PAOLI, Maria Célia. Memória, história e cidadania: o direito ao passado. Em: $O$ direito à memória: patrimônio histórico e cidadania. São Paulo: DPH, 1992, p. 25-28. Disponível em: https://arquivoememoria.files.wordpress.com/2009/04/memoria.pdf. Acesso em: 12 mar. 2020.

PINETEH, Ernest A. Moments of suffering, pain and resilience: Somali refugees' memories of home and journeys to exile. Em: Cogent Social Sciences, v. 3, 2017. Disponível em: https://www.researchgate.net/publication/319405140_Moments_of_suffering_pain_and_resili ence_Somali_refugees\%27_memories_of_home_and_journeys_to_exile. Acesso em: 7 mar. 2020.

QUIJANO, Aníbal. Colonialidade do poder, eurocentrismo e América Latina. Em: A colonialidade do saber: eurocentrismo e ciências sociais. Perspectivas latino-americanas. Edgardo Lander (org). Colección Sur Sur. Buenos Aires: CLACSO, 2005. Disponível em: http://biblioteca.clacso.edu.ar/clacso/sur-sur/20100624103322/12_Quijano.pdf. Acesso em: 3 mar. 2020.

RAJAGOPAL, Balakrishnan. El derecho Internacional desde abajo: el desarollo de los movimentos sociales y la resistência del tercer mundo. Bogotá: ILSA, 2005. Disponível em: https://www.researchgate.net/publication/309446590_El_derecho_internacional_desde_abajo _el_desarrollo_los_movimientos_sociales_y_la_resistencia_del_tercer_mundo_de_Balakrishn an_Rajagopal. Acesso em: 7 mar. 2020. 
REDCLIFT, Victoria. The demobilization of diaspora: history, memory and "latent identity". Em: Global Networks, v. 17, n. 4, p. 500-517, 2016. Disponível em: https://onlinelibrary.wiley.com/doi/full/10.1111/glob.12150. Acesso em: 7 mar. 2020.

SHAW, Malcolm. International Law. $5^{\text {a }}$ Ed. Cambridge: Cambridge University Press, 2003.

SILVA, Karine de Souza; BODENMULLER, Gustavo H. S. Eurocentrismo, hierarquias e colonialidade nas Relações Internacionais: A paz que eu não quero conservar. Em: SALATINI, Rafael; DIAS, Laércio Fidélis. (Org.). Reflexões sobre a paz: Paz e tolerância. 1ed. Marília, São Paulo: UNESP/Oficina Universitária/Cultura Acadêmica, 2018. Disponível em:

https://www.academia.edu/38326990/Eurocentrismo_hierarquias_e_colonialidade_nas_Relaç ões_Internacionais_a_paz_que_eu_não_quero_conservar_. Acesso em: 11 mar. 2020.

SILVA, Karine de Souza. A Declaração Universal dos Direitos Humanos, a ONU e a luta internacional contra o racismo: entre esperanças e desenganos. Em: Liliana Lyra Jubilut; Rachel de Oliveira Lopes. (Org.). Direitos humanos e vulnerabilidade e a declaração universal dos direitos humanos. $1^{\mathrm{a}}$ Ed. Santos: Editora Universitária Leopoldianum, 2018, p. 77-99. Disponível em: https://www.unisantos.br/wp-content/uploads/2018/12/DIREITOSHUMANOS-E-VULNERABILIDADE-E-A-DECLARA\%C3\%87\%C3\%830-UNIVERSALDOS-DIREITOS-HUMANOS.pdf. Acesso em: 11 mar. 2020.

TOURME-JOUANNET, Emmanuelle; PETERS, Anne. A forum for new research. Em: The Journal of the History of International Law, v. 16, p. 1-8, 2014. Disponível em: https://www.mpil.de/files/pdf3/Tourme_Jouannet_Peters_The_Journal_of the_History_of_In ternational_Law_A_forum_of_New_Research_JHIL_16_2014_1_85.pdf. Acesso em: 6 mar. 2020.

TOURME-JOUANNET, Emmanuelle. The International Law of Recognition. Em: European Journal of International Law, v. 24, n. 2, p. 667-690, 2013. Disponível em: https://www.researchgate.net/publication/273570341_The_International_Law_of_Recognitio n. Acesso em: 6 mar. 2020.

WALLERSTEIN, Immanuel. European Universalism: The Rhetoric of Power. New York: The New Press, 2006. 